\title{
A Comparison of the Photolytic and Photocatalytic Degradation of Triclosan: Identification of Transformation Products and Ecotoxicity Evaluation
}

\author{
Vitor S. Kosera, ${ }^{a}$ Elisabeth C. Lumbaque, ${ }^{\oplus a, b}$ Alexsandro Dallegrave, ${ }^{b}$ \\ Monike F. Gomes, ${ }^{c}$ Vinícius C. S. de Paula, ${ }^{c}$ Adriane M. de Freitas, ${ }^{c}$ \\ Carla Sirtori, ${ }^{c}$ Eduardo S. Chaves ${ }^{d}$ and Elaine R. L. Tiburtius*,a
}

${ }^{a}$ Universidade Estadual de Ponta Grossa, Av. General Carlos Cavalcanti, 4748, Uvaranas, 84030-900 Ponta Grossa-PR, Brazil

${ }^{b}$ Instituto de Química, Universidade Federal do Rio Grande do Sul, Av. Bento Gonçalves, 9500, Agronomia, 91509-900 Porto Alegre-RS, Brazil

'Departamento de Química e Biologia, Universidade Tecnológica Federal do Paraná, Rua Deputado Heitor Alencar Furtado, 5000, Ecoville, 81280-340 Curitiba-PR, Brazil

${ }^{d}$ Universidade Federal de Santa Catarina, Av. Des. Vitor Lima, 476, Trindade, 88040-900 Florianópolis-SC, Brazil

\begin{abstract}
Triclosan (5-chloro-2-(2,4-dichlorophenoxy)phenol) is commonly used as an antibacterial agent in various industrial products and is often detected in wastewater effluent. Comparison was made for triclosan degradation by photolysis and $\mathrm{TiO}_{2}$ photocatalysis (under $\mathrm{UV}$ irradiation $(125 \mathrm{~W})$ ) based on analysis of transformation products, together with ecotoxicity evaluation. The morphology of the $\mathrm{TiO}_{2}$ was characterized by X-ray diffractometry (XRD) and field emission gun-scanning electron microscopy (FEG-SEM). Triclosan quantitation was performed by high performance liquid chromatography (HPLC). The optimal condition was obtained using a response surface model and desirability profile. The initial concentration of triclosan used in all the experiments was $10 \mathrm{mg} \mathrm{L}^{-1}$ to achieve comprehensive identification of transformation products. The optimal experimental condition was $30 \mathrm{mg} \mathrm{L}^{-1} \mathrm{TiO}_{2}$ at $\mathrm{pH} 10$. The photocatalytic system achieved $>99 \%$ triclosan degradation at $30 \mathrm{~min}$ of reaction. The mineralization rates by photolysis and photocatalysis were 25 and $90 \%$, respectively. A total of 27 transformation products were identified using liquid chromatography quadrupole time of flight mass spectrometry (QTOF MS), being that 25 were new structures, not previously reported in the literature. Ecotoxicity assays demonstrated that triclosan and some of the major transformation products did not cause deleterious effects towards Lactuca sativa and Daphnia magna after $16 \mathrm{~h}$ of treatment.
\end{abstract}

Keywords: triclosan, photolysis, heterogeneous photocatalysis, transformation products, Daphnia magna, Lactuca sativa

\section{Introduction}

Triclosan (TCS, 5-chloro-2-(2,4-dichlorophenoxy) phenol) is an antimicrobial and fungicidal compound that is widely used in personal care products, textiles, soaps, and first aid products. TCS has been found in wastewaters and surface waters at concentrations ranging from $\mathrm{ng} \mathrm{L}^{-1}$ to $\mu \mathrm{g} \mathrm{L}{ }^{-1}$, and has been identified in human milk and urine. ${ }^{1,2}$ As an emerging contaminant, the occurrence of TCS in ecosystems has attracted considerable attention, due to

*e-mail: erltiburtius@gmail.com risks to humans and aquatic organisms such as algae, invertebrates, and fish, ${ }^{3}$ even at trace concentrations.

Conventional wastewater treatment systems (such as biological and physical-chemical processes) are unable to provide efficient degradation and mineralization of TCS. Therefore, an alternative is to use advanced oxidation processes (AOPs), such as $\mathrm{UV} / \mathrm{TiO}_{2}$, which involve a series of different mechanisms for the generation of powerful reactive oxygen species (ROSs). Under UV light, these species are able to oxidize contaminants into small organic molecules by means of photo-oxidation of $\mathrm{H}_{2} \mathrm{O} / \mathrm{HO}^{-}$by holes $\left(\mathrm{h}^{+}\right)$of the semiconductor valence band (VB), as well 
as by photo-reduction of $\mathrm{H}_{2} \mathrm{O}_{2}$ or $\mathrm{O}_{2}$ by electrons $\left(\mathrm{e}^{-}\right)$of the semiconductor conduction band (CB).,5

There have been many studies focused on the photocatalytic degradation of emerging contaminants such as TCS. However, few of them have investigated the transformation products (TPs) generated during the processes or have attempted to elucidate their persistence and toxicity. In particular, dioxins and chlorophenols may be associated with the TCS presence in different water matrices. These substances are regulated in many countries, ${ }^{1,6,7}$ which emphasize the importance of identifying possible TPs with structural groups that are the same as, or similar to, those of such compounds.

The use of chromatographic techniques coupled with high resolution mass spectrometry (HRMS) tools can enable the elucidation of potential structures of TPs generated during treatment processes, based on the information contained in complete spectra. Exact mass analysis can assist in identifying TPs that do not have a commercial analytical standard available and that have not yet been mentioned in the literature. Analyses of unknown compounds can be performed that allow subsequent retrospective evaluation of the data, at any time, without the need of further analysis. Hence, the identification of TPs has been made feasible by time-of-flight mass spectrometry (TOF MS) and quadrupole time-of-flight mass spectrometry (QTOF MS) data analysis for different samples and different environmental matrices. ${ }^{8,9}$

In this study, triclosan was selected as the target micropollutant for evaluation of degradation and mineralization by photolysis and by heterogeneous photocatalysis using $\mathrm{UV} / \mathrm{TiO}_{2}$. The TPs generated during the two processes were identified by liquid chromatographyhybrid quadrupole time-of-flight mass spectrometry (LC-QTOF MS) and the degradation steps were proposed. The toxicities of triclosan and the irradiated samples were evaluated using Daphnia magna and Lactuca sativa seeds.

\section{Experimental}

\section{Chemicals}

All chemicals and reagents used in this work were analytical grade. For the experimental design and optimization of parameters, a triclosan (Merck, Frankfurt, Germany) stock solution (100 $\mathrm{mg} \mathrm{L}^{-1}$ ) was prepared by dissolving a suitable amount in acetonitrile:water $\left(70: 30 \mathrm{v} \mathrm{v}^{-1}\right)$ to improve the solubility of TCS in different $\mathrm{pH}$ range. However, the working solution for all experiments under optimal conditions (basic $\mathrm{pH}$ ) was prepared by directly dissolving the TCS mass in ultrapure water
(Milli-Q ${ }^{\circledR}$ system) since triclosan is easily soluble in alkaline solutions.

$\mathrm{TiO}_{2}(100 \%$ anatase, particle size $\geq 250 \mathrm{~nm}$, band gap of $3.22 \mathrm{eV}$ ) was obtained from Quimex (Uberaba, Brazil). Acetonitrile (HPLC grade from Vetec, Rio de Janeiro, Brazil) used in the chromatographic analysis was from Vetec (Goiânia, Brazil). Sodium hydroxide (Neon, Suzano, Brazil) and sulfuric acid (Química Moderna, Barueri, Brazil) were used for $\mathrm{pH}$ adjustments.

\section{Analysis and instrumentation}

The morphology of $\mathrm{TiO}_{2}$ was characterized by X-ray diffractometry (Model Ultima IX, Rigaku, Tokyo, Japan). Field emission gun-scanning electron microscopy (FEG-SEM) analyses were performed using a Mira 3 instrument (TESCAN, Brun, Republic of Czech).

The TCS quantitation was performed by high performance liquid chromatography (HPLC), using a YL Clarity 9100 instrument (Anyangcheondon, Republic of Korea). The calibration range was from 0.1 to $10.00 \mathrm{mg} \mathrm{L}^{-1}$ (the upper value is the maximum solubility of TCS at $25{ }^{\circ} \mathrm{C}$ ). The HPLC system was equipped with a reversed phase Shimadzu VP-ODS (Kyoto, Japan) C18 column $(250 \times 4.6 \mathrm{~mm}, 5 \mu \mathrm{m})$. The mobile phase was acetonitrile:water $\left(70: 30 \mathrm{v} \mathrm{v}^{-1}\right)$, at a flow rate of $1 \mathrm{~mL} \mathrm{~min}^{-1}$, and the detector wavelength was $280 \mathrm{~nm}$. These conditions resulted in a linear response, with $\mathrm{R}^{2}$ (correlation coefficient) of 0.99 , limits of detection (LOD) and quantification (LOQ) of 0.1 and $1.0 \mathrm{mg} \mathrm{L}^{-1}$, respectively, and relative standard deviation (RSD) of $4.2 \%$.

Dissolved organic carbon (DOC) was determined using a Shimadzu TOC-L CSH analyzer (Kyoto, Japan) with a working range from 0.1 to $50 \mathrm{mg} \mathrm{L}^{-1}$. The technique showed a linear response with $\mathrm{R}^{2}$ of $0.999, \mathrm{LOD}$ of $0.1 \mathrm{mg} \mathrm{L}^{-1}$, LOQ of $0.5 \mathrm{mg} \mathrm{L}^{-1}$, and RSD of $2.0 \%$.

The TPs produced during the photolysis and photocatalysis processes were monitored using a Shimadzu Nexera X2 UHPLC (Kyoto, Japan) system connected to an Impact II QTOF mass spectrometer (Bruker-Daltonics, Machassachusets, USA). The UHPLC system was equipped with a Phenomenex reversed phase Luna ${ }^{\circledR}$ Omega C18 analytical column $(2.1 \times 50 \mathrm{~mm}, 1.6 \mu \mathrm{m})$ maintained at $35{ }^{\circ} \mathrm{C}$. The mobile phase was a mixture of methanol acidified with $0.1 \%\left(\mathrm{v} \mathrm{v}^{-1}\right)$ formic acid (eluent $\left.\mathrm{A}\right)$ and $\mathrm{H}_{2} \mathrm{O}$ acidified with $0.1 \%\left(\mathrm{v} \mathrm{v}^{-1}\right)$ formic acid (eluent $\mathrm{B}$ ). The elution gradient started at $10 \%\left(\mathrm{v} \mathrm{v}^{-1}\right)$ of eluent $\mathrm{A}$, maintained for $2 \mathrm{~min}$, followed by an increase during $8 \mathrm{~min}$ to $90 \%\left(\mathrm{v} \mathrm{v}^{-1}\right)$ eluent $\mathrm{A}$, maintained for $1 \mathrm{~min}$, and a linear decrease during 4 min to $10 \%\left(\mathrm{v} \mathrm{v}^{-1}\right)$ eluent $\mathrm{A}$, maintained for $5 \mathrm{~min}$. The flow rate was $0.28 \mathrm{~mL} \mathrm{~min}^{-1}$ and the injection 
volume was $10 \mu \mathrm{L}$. The QTOF MS was operated in negative ionization mode, under the following conditions: end plate offset of $500 \mathrm{~V}$, capillary at $2,500 \mathrm{~V}$, nebulizer at 3 bar $\left(\mathrm{N}_{2}\right)$, drying gas at $9.0 \mathrm{~L} \mathrm{~min}{ }^{-1}\left(\mathrm{~N}_{2}\right)$, and gas temperature of $200{ }^{\circ} \mathrm{C}$. Broadband collision-induced dissociation (bbCID) mode was used to provide simultaneous MS and MS/MS spectra. All the MS information was recorded over the $\mathrm{m} / \mathrm{z}$ range 55-1000, using a scan rate of $2 \mathrm{~Hz}$. The bbCID mode allowed the operation with two different collision energies: low collision energy of $10 \mathrm{eV}$ and high collision energy of $20 \mathrm{eV}$ (to obtain the MS/MS spectra). External calibration of QTOF MS with a sodium formate solution was performed before each injection. Data treatment was performed with Data Analysis 4.2 software. The mass measurement error was $<5 \mathrm{ppm}$, and the theoretical and measured isotopic patterns were compared for better identification of the TCS transformation products.

\section{Photolytic and photocatalytic experiments}

The degradation and mineralization assays employed an initial TCS concentration of $10.0 \mathrm{mg} \mathrm{L}^{-1}$, prepared in ultrapure water. Although this concentration was higher than found in the environment, its use enabled identification of TPs without the need of extraction procedures (such as solid phase extraction (SPE)), as well as evaluation of the mineralization capacity of the system by total organic carbon (TOC) analysis.

The experiments were performed in a conventional glass reactor $(250 \mathrm{~mL})$, at a constant temperature of $25{ }^{\circ} \mathrm{C}$ and with $\mathrm{pH}$ adjustment. A high-pressure mercury lamp $(125 \mathrm{~W}$, UV irradiation from 180 to $400 \mathrm{~nm}$ ) was inserted into the solution, using a quartz jacket, and a magnetic stirrer was used to disperse the catalyst (Figure S1 in the Supplementary Information (SI) section). For the photocatalysis experiments, $\mathrm{TiO}_{2}$ in suspension was added to the reactor. The photolysis experiments were performed without the use of $\mathrm{TiO}_{2}$.

The TCS percentage removal was used as the response, calculated according to equation $1:^{7}$

$\operatorname{Removal}(\%)=\left[\mathrm{C}_{\mathrm{TCS}} / \mathrm{C}_{\mathrm{TCS}}\right] \times 100$

where, $\mathrm{C}_{\mathrm{TCS}}$ is the TCS concentration at a given time and $\mathrm{C}_{\mathrm{TCS}}$ is the initial TCS concentration.

The optimal condition was obtained using a response surface model and desirability profile, employing Statistica version $7.0^{10}$ software (StatSoft ${ }^{\circledR}$ Inc., USA).

\section{Ecotoxicity assays}

For the ecotoxicity evaluation, samples were collected at different times $(0,5,10,30,60,120,240,360,480,960$, and $1,440 \mathrm{~min}$ ), in clean glass flasks. The samples were filtered through a $0.45 \mu \mathrm{m}$ membrane to remove $\mathrm{TiO}_{2}$ and $\mathrm{pH}$ value was adjusted to 6-7, when necessary. Two bioassays were selected, employing Lactuca sativa seeds (phytotoxicity test) and Daphnia magna (acute ecotoxicity test).

The phytotoxicity tests based on seed germination and root elongation were conducted according to standardized protocols, ${ }^{11,12}$ in Petri dishes lined with filter paper, using 15 seeds of Lactuca sativa (Boston White variety) and $4 \mathrm{~mL}$ of the sample. Glyphosate solution $\left(6 \% \mathrm{v} \mathrm{v}^{-1}\right)$ and ultrapure water were used as positive and negative controls, respectively. The assays were performed in triplicate, with incubation of the seeds for $120 \mathrm{~h}$ at $22 \pm 2{ }^{\circ} \mathrm{C}$, in the dark. At the end of the test, the number of germinated seeds and the root elongation data were used to calculate the germination index $(\mathrm{GI})^{13}$ and the relative growth index (RGI), respectively. ${ }^{11,13}$ Statistical evaluation of the data was performed with BioEstat 5.3 software. ${ }^{14}$ The data normality was confirmed using the Kolmogorov-Smirnov test, followed by application of one-way analysis of variance (ANOVA) and the Dunnet test $(p<0.01)$.

The acute toxicity assays employing $D$. magna were performed according to the methodology described in NBR $12713 .{ }^{15}$ Ten neonates $(6-24 \mathrm{~h})$ were used for each of three replicates. The samples were diluted in culture medium, as required, to give concentrations of 100, 50, $25,12.5$, and $6.25 \%\left(\mathrm{v} \mathrm{v}^{-1}\right)$. The negative control was the standard medium and the positive control was potassium chloride (Vetec, Goiânia, Brazil). All the tests were performed at $20 \pm 2{ }^{\circ} \mathrm{C}$. After exposure for $48 \mathrm{~h}$, the number of immobile organisms was recorded. The results were expressed in terms of toxic units (TU), defined as $100 / \mathrm{EC}_{50}$ (50\% effective concentration). The $\mathrm{EC}_{50}$ value was calculated using the Probit method.

\section{Results and Discussion}

\section{Experimental design and optimization of parameters}

The TCS photocatalytic degradation was performed using $\mathrm{TiO}_{2}$ (P25 Degussa) as catalyst, selected based on previous results reported in the literature. ${ }^{16} \mathrm{~A} 2^{2}$ factorial design with 2 levels and one central point was used to obtain the most appropriate experimental conditions, with evaluation of the relationship between the studied variables. The response of experimental design was reported as the percentage of TCS removal. The independent variables were the catalyst concentration and $\mathrm{pH}$ value. Table 1 shows the variation of the response under different experimental conditions, from which it can be seen that the TCS 
Table 1. Factorial design matrix with two independent variables (coded and experimental values) and the responses for a 10 min reaction time

\begin{tabular}{|c|c|c|c|c|c|}
\hline \multirow{2}{*}{ Assay } & \multicolumn{2}{|c|}{ Coded variable } & \multicolumn{2}{|c|}{ Experimental variable } & \multirow{2}{*}{$\begin{array}{l}\text { Response / \% } \\
\text { (TCS removal) }\end{array}$} \\
\hline & $\mathrm{X}_{1}$ & $\mathrm{X}_{2}$ & $\mathrm{pH}$ & $\mathrm{TiO}_{2} /\left(\mathrm{mg} \mathrm{L}^{-1}\right)$ & \\
\hline 1 & -1 & -1 & 4.0 & 30.0 & 56.1 \\
\hline 2 & +1 & -1 & 10.0 & 30.0 & 85.2 \\
\hline 3 & -1 & +1 & 4.0 & 100.0 & 67.5 \\
\hline 4 & +1 & +1 & 10.0 & 100.0 & 62.8 \\
\hline 5 & 0 & 0 & 7.0 & 65.0 & 61.5 \\
\hline
\end{tabular}

degradation percentage increased with $\mathrm{pH}$ value increase and $\mathrm{TiO}_{2}$ concentration decrease.

The highest degradation rate was obtained in assay 2 (85.2\%). As shown in the Pareto chart of the effects (Figure S2, SI section), the interaction between the variables ( $\mathrm{pH}$ and catalyst) was statistically important for the treatment. The Pareto chart also shows that the catalyst and the $\mathrm{pH}$ value had an antagonist effect, confirming the results shown in the response surface (Figure 1a) and the desirability profile (Figure 1b). The obtained model was able to explain more than $85 \%$ of the data variance. The desirability profile, ranging from 0.0 (undesirable) to 1.0 (very desirable), provided an indication of the best experimental conditions in the explored range, with a desirability value of 1.0 for $\mathrm{pH} 10$ and catalyst concentration of $30 \mathrm{mg} \mathrm{L}^{-1}$. By applying regression analysis to the experimental data, the results could be described by equation 2 :

TCS removal $(\%)=57.4938+2.0333 \mathrm{X}_{1}-0.0786 \mathrm{X}_{2}$

In order to verify the accuracy of the model developed (equation 2), the predicted value $(75.5 \%)$ was compared with the experimental value $(85.2 \%)$; the experimental value was greater than the theoretical value to show the optimization. Then, the predicted model agrees with the experimental data. Therefore, this condition was selected in the subsequent experiments.

According to the results, an alkaline medium was most favorable for the TCS degradation using $\mathrm{UV} / \mathrm{TiO}_{2}$. The $\mathrm{pH}$ effect on the surface charge of the catalyst depends on the point of zero charge $\left(\mathrm{p}_{\mathrm{zc}}\right.$ is the $\mathrm{pH}$ at which the surface is neutral). The $\mathrm{p}_{\mathrm{zc}}$ value of $\mathrm{TiO}_{2}$ is at around $\mathrm{pH} 6.5,{ }^{17}$ so the semiconductor charge varies with $\mathrm{pH}$ (equations 3 and 4): ${ }^{18}$

At $\mathrm{pH}<\mathrm{p}_{\mathrm{zc}}: \mathrm{TiOH}+\mathrm{H}^{+} \rightarrow \mathrm{TiOH}_{2}^{+}$

At $\mathrm{pH}>\mathrm{p}_{\mathrm{zc}}: \mathrm{TiOH}+\mathrm{OH}^{-} \rightarrow \mathrm{TiO}^{-}+\mathrm{H}_{2} \mathrm{O}$

Therefore, the $\mathrm{TiO}_{2}$ surface is negatively charged under alkaline conditions $(\mathrm{pH}>6.5)$. Furthermore, TCS can be transformed into the triclosan anion at basic $\mathrm{pH}(\mathrm{pH}>7.7)$ since the $\mathrm{p} K_{\mathrm{a}}$ value of triclosan is $7.68 .{ }^{19}$ Therefore, under the experimental conditions ( $\mathrm{pH} 10$ ), the adsorption of TCS on $\mathrm{TiO}_{2}$ was less effective due to the repulsive force acting between TCS and the $\mathrm{TiO}_{2}$ catalyst.

The photocatalytic reaction starts with the absorption of photons with energy equal to or higher than the band gap of the semiconductor, producing electron-hole $\left(\mathrm{e}^{-} / \mathrm{h}^{+}\right)$pairs (equation 5). The valence band is highly oxidizing, while the conduction band is highly reducing. ${ }^{16}$ In photocatalysis, $\mathrm{pH}$ can also affect the reaction of reactive oxygen species (ROS) from $\mathrm{H}_{2} \mathrm{O} / \mathrm{HO}^{-}$and $\mathrm{TiO}_{2}$. ROS including $\mathrm{HO}^{\circ}, \mathrm{H}_{2} \mathrm{O}_{2}$, $\mathrm{O}_{2}^{--}$, and ${ }^{1} \mathrm{O}_{2}$ may be generated by the oxidation of $\mathrm{H}_{2} \mathrm{O}$. On the other hand, the reduction of $\mathrm{O}_{2}$ generates $\mathrm{O}_{2}{ }^{--}, \mathrm{HO}{ }^{*}$, and $\mathrm{H}_{2} \mathrm{O}_{2}{ }^{20} \mathrm{At} \mathrm{pH}<9.9$, the reduction potential of $\mathrm{O}_{2}{ }^{-2}$ is more positive than that of $\mathrm{H}_{2} \mathrm{O}_{2}\left(\mathrm{E}^{0}\left(\mathrm{O}_{2}^{--}, 2 \mathrm{H}^{+} / \mathrm{H}_{2} \mathrm{O}_{2}\right)=+1.72>\mathrm{E}^{0}\right.$ $\left.\left(\mathrm{H}_{2} \mathrm{O}_{2}, \mathrm{H}^{+} / \mathrm{HO}^{*}\right)=+1.14\right)$. Consequently, the reduction of $\mathrm{O}_{2}{ }^{--}$ to $\mathrm{H}_{2} \mathrm{O}_{2}$ (equation 6) is thermodynamically more favorable than the reduction of $\mathrm{H}_{2} \mathrm{O}_{2}$ to $\mathrm{HO}^{\circ}$. In solution, the oxidation of $\mathrm{H}_{2} \mathrm{O}_{2}$ with a photoinduced valence band hole $\left(\mathrm{h}^{+}\right)$produces $\mathrm{O}_{2}^{--}$(equation 7), and since $\mathrm{H}_{2} \mathrm{O}_{2}$ is also a stable intermediate in the reduction of $\mathrm{O}_{2}$ to $\mathrm{H}_{2} \mathrm{O}$, one-step reduction of $\mathrm{H}_{2} \mathrm{O}_{2}$ may generate the $\mathrm{HO}^{-}$radical (equation 8), or the $\mathrm{O}_{2}^{-{ }^{-}}$produced could also react with $\mathrm{H}_{2} \mathrm{O}_{2}$ (equation 9). In addition, surface complexes of $\mathrm{H}_{2} \mathrm{O}_{2}-\mathrm{TiO}_{2}$ are formed, extending the photoresponse of $\mathrm{TiO}_{2}$ and resulting in electron transfer from surface complexes to the conduction band of $\mathrm{TiO}_{2}{ }^{21}$ The ROS generated in the photocatalysis lead to the degradation and mineralization of TCS.

$\mathrm{TiO}_{2}+\mathrm{h} \stackrel{\lambda<385 \mathrm{~nm}}{\longrightarrow} \mathrm{e}_{\mathrm{CB}}^{-}+\mathrm{h}_{\mathrm{vb}}^{+}$
$\mathrm{O}_{2}+2 \mathrm{H}^{+}+\mathrm{e}_{\mathrm{CB}}^{-} \rightarrow \mathrm{H}_{2} \mathrm{O}_{2}$
$\mathrm{H}_{2} \mathrm{O}_{2}+\mathrm{h}_{\mathrm{vb}}^{+} \rightarrow \mathrm{O}_{2}^{-}+2 \mathrm{H}^{+}$
$\mathrm{H}_{2} \mathrm{O}_{2}+\mathrm{e}_{\mathrm{CB}}^{-} \rightarrow \mathrm{HO}^{-}+\mathrm{HO}^{-}$
$\mathrm{H}_{2} \mathrm{O}_{2}+\mathrm{O}_{2}^{-} \rightarrow \mathrm{HO}^{-}+\mathrm{HO}^{-}+\mathrm{O}_{2}$

where $\mathrm{e}_{\mathrm{CB}}^{-}$and $\mathrm{h}_{\mathrm{vb}}^{+}$are electron and hole trapping states near the conduction band bottom and valance band top of $\mathrm{TiO}_{2}$, respectively.

Additionally, the use of high dosages of $\mathrm{TiO}_{2}$ catalyst can result in the particles preventing penetration of $\mathrm{UV}$ radiation, with increased light scattering, while phenomena such as particle agglomeration (particle-particle interactions) can decrease the surface area of the catalyst. ${ }^{22-25}$

\section{Degradation, mineralization, and kinetic studies}

Degradation and mineralization assays were performed under the best conditions for TCS degradation predicted from the factorial design procedure $\left(10 \mathrm{mg} \mathrm{L}^{-1} \mathrm{TCS}\right.$, $30 \mathrm{mg} \mathrm{L}^{-1} \mathrm{TiO}_{2}$, and $\mathrm{pH} 10$ ). The performances of the adsorption, photolysis, and photocatalysis processes were 
(a)

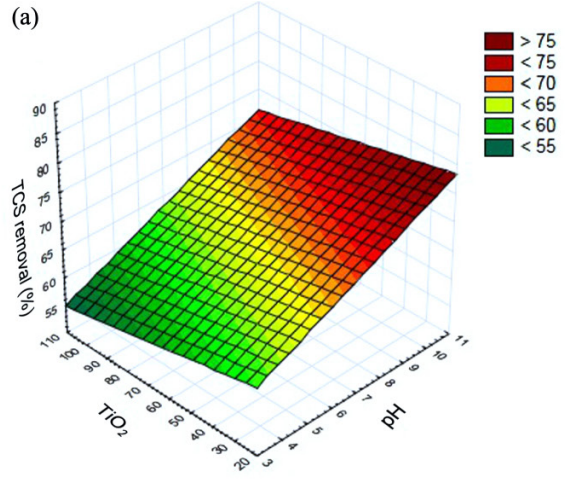

(b)

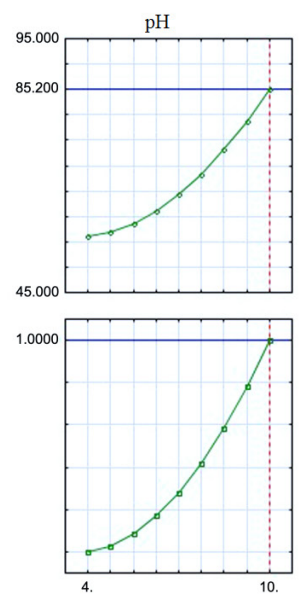

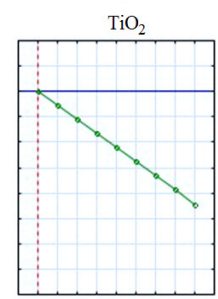
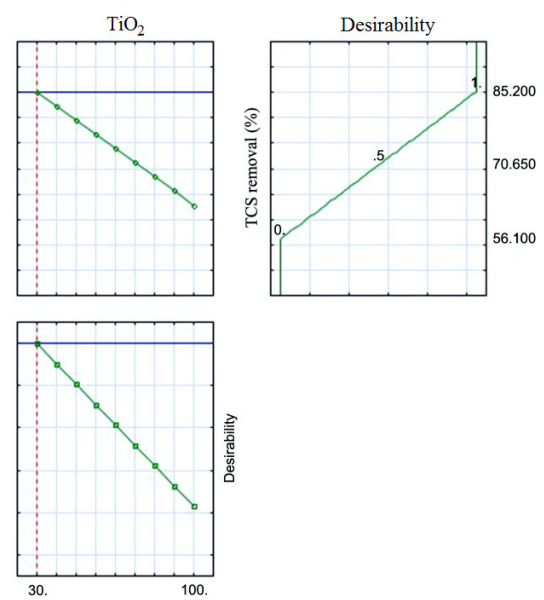

Figure 1. (a) Response surface plot (3D) and (b) profiles for predicted values and desirability.
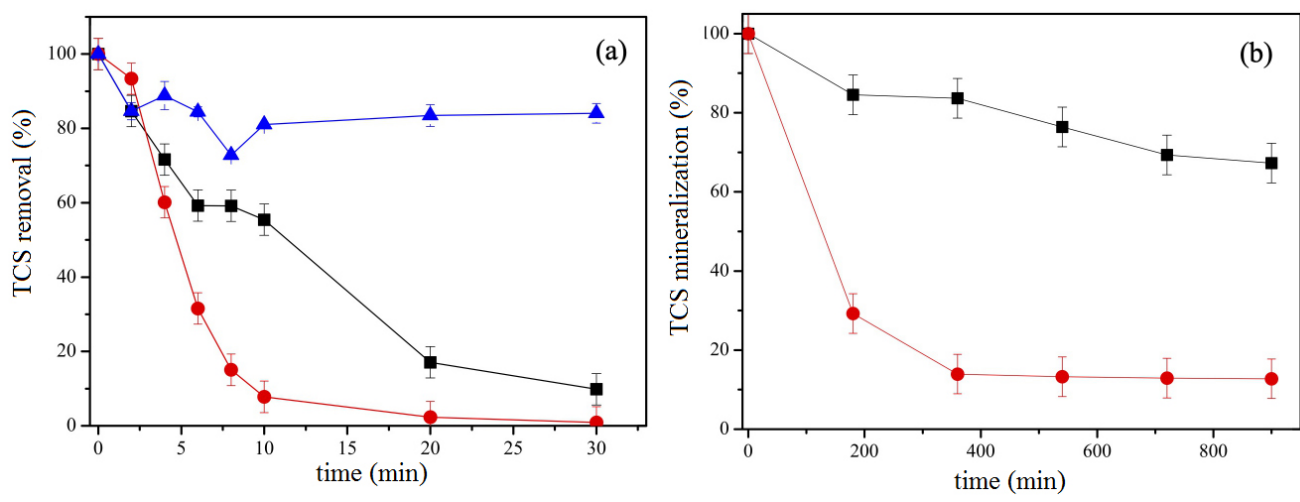

Figure 2. (a) TCS removal and (b) TCS mineralization by adsorption $(\mathbf{\Delta})$, photolysis $\mathrm{TiO}_{2}=30.0 \mathrm{mg} \mathrm{L}^{-1}$, and $\mathrm{pH} 10$.

monitored using the TCS concentration decrease. The results are shown in Figure 2a.

The photocatalysis process resulted in almost $60 \%$ TCS removal after 6 min of irradiation, compared to $31 \%$ removal by photolysis, demonstrating the strong effect of $\mathrm{TiO}_{2}$ on TCS removal. The degradation observed using photolysis could be attributed to TCS deprotonation since higher photodegradation rates result from higher quantum yields $(\Phi)$ obtained due to greater light absorption by anionic forms of the contaminant. ${ }^{26}$ Martínez-Zapata et al. ${ }^{27}$ also reported that photolysis increased when the medium was more basic because the anionic form (phenolate) is more reactive than the neutral form (phenolic). Furthermore, degradation and mineralization are influenced by the TPs generated in each process (further information is provided in the next section).

The TCS removal efficiency can vary according to the operational conditions and parameters such as the initial TCS concentration, $\mathrm{pH}$, ions, humic acids, and $\mathrm{TiO}_{2}$ dosage. ${ }^{28}$ Nonetheless, similar results have been reported previously with photocatalysis using $\mathrm{TiO}_{2}$ being significantly more effective than photolysis. Son et al. ${ }^{16}$ studied TCS degradation by photolysis and photocatalysis, using a mercury UV-A lamp and $\mathrm{TiO}_{2}\left(\mathrm{P}-25,100 \mathrm{mg} \mathrm{L}^{-1}\right)$, and also observed a significant influence of $\mathrm{TiO}_{2}$ on the removal of TCS. On the other hand, Iovino et al. ${ }^{28}$ found that direct photolysis of TCS (at concentrations between 15.5 and $61.8 \mu \mathrm{M}$ ) was more effective for anionic TCS species than for the molecular form, with TCS removals of 99 and $95 \%$ at $\mathrm{pH} 10$ and 6, respectively, using an irradiation time shorter than $30 \mathrm{~min}$.

In order to compare the obtained results, the reaction orders and the half-life times were determined. These parameters provide important information and can assist in evaluating the advantages that catalysts can bring to the reaction since gains in the degradation rate are directly reflected in shorter half-life times. The LangmuirHinshelwood kinetic model is commonly used to describe the kinetics of heterogeneous photocatalysis processes, considering the relationship between the degradation rate $\left(\mathrm{R}_{\mathrm{d}}^{2}\right)$ and the concentration (C) of a pollutant in water, according to the reaction time. ${ }^{29,30}$ When the adsorption in a 
photocatalytic process is relatively weak and/or the reactant concentration is low, the kinetics of the degradation process can be simplified to the pseudo-first order model, with an apparent first order rate constant, $\mathrm{k}_{\mathrm{app}} \cdot{ }^{31}$

For the heterogeneous photocatalysis process, the TCS degradation kinetics assays revealed a linear relationship between $\ln \left(\mathrm{C}_{0} / \mathrm{C}\right)$ and irradiation time, showing that this process followed the Langmuir-Hinshelwood model. For photolysis, the first order kinetic model provided a good fit to the data, indicating that the photodegradation had a linear dependence on only the TCS concentration. The correlation coefficients $\left(\mathrm{R}^{2}\right)$, rate constants $\left(\mathrm{k}_{\text {app }}\right)$, and half-life times $\left(t_{1 / 2}\right)$ for the photocatalysis and photolysis processes are shown in Table 2.

The $\mathrm{k}_{\text {app }}$ values for photocatalysis and photolysis were 0.6208 and $0.0800 \mathrm{~min}^{-1}$, respectively. Comparison of the $\mathrm{t}_{1 / 2}$ values confirmed that the TCS degradation was faster for the photocatalysis process than for photolysis. Although photolysis provided significant TCS removal at basic $\mathrm{pH}$, the rate constant and $t_{1 / 2}$ values indicated that TCS was mainly degraded by the heterogeneous reactions.

Mineralization is defined as the quantitative conversion of organic compounds to stable inorganic substances such as water, carbon dioxide, and inorganic anions. ${ }^{2} \mathrm{UV}$ irradiation can break bonds in organic compounds by direct photolysis, in which photons degrade chemicals, or by indirect reactions involving several oxidative and reductive species $\left(\mathrm{h}^{+}, \mathrm{e}^{-}, \mathrm{HO}, \mathrm{O}_{2}^{-\bullet}, \mathrm{HO}_{2} \cdot \mathrm{H}_{2} \mathrm{O}_{2}\right.$, and $\left.{ }^{1} \mathrm{O}_{2}\right)$ generated in $\mathrm{UV} / \mathrm{TiO}_{2}$ photocatalysis. ${ }^{32}$ These species can react with organic contaminants. ${ }^{32}$

DOC analysis was used to determine the mineralization degrees achieved in the photocatalysis and photolysis processes. The results (Figure $2 b$ ) showed that the TCS degradation performance was almost the same for the two processes, while the rates of mineralization differed significantly. The $\mathrm{TiO}_{2}$ presence had a positive effect on the mineralization rate, with over $90 \%$ mineralization achieved in 900 min, while mineralization lower than $50 \%$ was obtained using photolysis alone. The photolysis reaction could be satisfactorily fitted using the apparent first order model, with a half-life time of $8.66 \mathrm{~min}$, while the photocatalysis process was fitted using the apparent pseudo-first order model, with a half-life time of $1.12 \mathrm{~min}$ (Table 2).

The Langmuir-Hinshelwood kinetic model was used to describe the mineralization in the photocatalysis process, but the fit was poorer than for the mineralization by photolysis, indicating that the behavior of TCS mineralization by photocatalysis did not obey this type of kinetic model.

Chan and $\mathrm{Chu}^{33}$ proposed a kinetic model to describe a process with a high degradation rate in the first few minutes of reaction, followed by slow degradation up to the end of the treatment. The following mathematical model was used to simulate the kinetics of the reaction (equation 10):

$\frac{t}{1-\left(C / C_{0}\right)}=\rho+\sigma t \leftrightarrow \frac{d\left(C / C_{0}\right)}{d t}=\frac{-\rho}{(\rho+\sigma t)^{2}}$

where, $\mathrm{C}$ is the TCS concentration remaining in the system after a reaction time $\mathrm{t}(\mathrm{min}), \mathrm{C}_{0}$ is the initial concentration, and the parameters $\rho(\min )$ and $\sigma$ are characteristic constants related to the reaction kinetics and the degradation capacity, respectively. Therefore, a higher value of $1 / \rho$ indicates a faster initial TCS degradation rate. When $t$ is high and approaches infinity, the reciprocal of the constant $\sigma$ is the theoretical maximum TCS removal fraction. The corresponding regression resulted in a high $\mathrm{R}^{2}$ value of 0.99 (Table 2), indicating that the TCS mineralization behavior was satisfactorily described by the proposed model.

However, it is important to note that high TCS concentrations were used for determination of the TPs, which would have affected the removal percentages and, consequently, the kinetic data. ${ }^{34}$ Studies with lower concentrations (close to those found in real matrices) would be expected to find kinetic parameter values different to those obtained here.

\section{Transformation products}

A total of 27 TPs were identified in the photocatalysis and photolysis processes (Tables $\mathrm{S} 1$ and S2, in the SI

Table 2. Kinetic data for transformation product (TP) degradation and mineralization

\begin{tabular}{|c|c|c|c|c|c|}
\hline Process & Study & Reaction order & $\mathrm{R}^{2}$ & $\mathrm{k}_{\mathrm{app}} / \min ^{-1}$ & $\mathrm{t}_{1 / 2} / \mathrm{min}^{-1}$ \\
\hline Photolysis & degradation & first order & 0.98 & 0.0800 & 8.66 \\
\hline Photocatalysis & degradation & pseudo-first order & 0.95 & 0.6208 & 1.12 \\
\hline Photolysis & mineralization & pseudo-first order & 0.98 & $4.587 \times 10^{-4}$ & $1.51 \times 10^{3}$ \\
\hline Photocatalysis & mineralization & $\begin{array}{l}\text { mathematical model by } \\
\text { Chan and } \mathrm{Chu}^{33}\end{array}$ & 0.99 & $\begin{array}{c}\rho^{-1}=0.37 \mathrm{~min}^{-1} \\
\sigma=1.14\end{array}$ & \\
\hline
\end{tabular}

$\mathrm{k}_{\mathrm{app}}$ : first order rate constant; $\mathrm{t}_{1 / 2}$ : half-life time; $\mathrm{R}^{2}$ : correlation coefficient; $\rho$ : characteristic constant related to the reaction kinetics; $\sigma$ : characteristic constant related to degradation capacity. 
section). The elemental compositions, theoretical and experimental ion masses, errors (below $5 \mathrm{ppm}$ in most cases), and double bond equivalents (DBEs) of the TPs were provided by the software.

In the photocatalysis process, there was identification of the following: five isomers of $\mathrm{C}_{18} \mathrm{H}_{9} \mathrm{C}_{12} \mathrm{O}_{5}(\mathrm{~m} / z 374.9833$; TPs 1-5), $\mathrm{C}_{12} \mathrm{H}_{7} \mathrm{C}_{12} \mathrm{O}_{2}$ (m/z 252.9829; TP 6), $\mathrm{C}_{24} \mathrm{H}_{11} \mathrm{C}_{14} \mathrm{O}_{5}$ $\left(\mathrm{m} / z\right.$ 518.936; TP 7), two isomers of $\mathrm{C}_{24} \mathrm{H}_{12} \mathrm{C}_{15} \mathrm{O}_{4}$ $\left(\mathrm{m} / \mathrm{z}\right.$ 538.9184; TPs 8-9), two isomers of $\mathrm{C}_{24} \mathrm{H}_{11} \mathrm{C}_{14} \mathrm{O}_{6}$ $\left(\mathrm{m} / \mathrm{z}\right.$ 534.9315; TPs 10-11), $\mathrm{C}_{12} \mathrm{H}_{8} \mathrm{C}_{1} \mathrm{O}_{2}(\mathrm{~m} / 2$ 219.0218; TP 12$)$, $\mathrm{C}_{12} \mathrm{H}_{5} \mathrm{C}_{12} \mathrm{O}_{4}\left(\mathrm{~m} / z\right.$ 282.957; TP 13), $\mathrm{C}_{12} \mathrm{H}_{6} \mathrm{ClO}_{4}(\mathrm{~m} / z$ 248.996; TP 14), two isomers of $\mathrm{C}_{7} \mathrm{H}_{4} \mathrm{ClO}_{3}(\mathrm{~m} / \mathrm{z}$ 170.9854; TPs 15-16), $\mathrm{C}_{12} \mathrm{H}_{8} \mathrm{ClO}_{3}\left(\mathrm{~m} / z\right.$ 235.0167; TP 17), $\mathrm{C}_{14} \mathrm{H}_{7} \mathrm{C}_{12} \mathrm{O}_{6}$ $\left(\mathrm{m} / z\right.$ 340.9625; TP 18), $\mathrm{C}_{12} \mathrm{H}_{8} \mathrm{ClO}_{4}(\mathrm{~m} / \mathrm{z}$ 251.0117; TP 19), $\mathrm{C}_{12} \mathrm{H}_{8} \mathrm{ClO}_{5}\left(\mathrm{~m} / \mathrm{z}\right.$ 267.0066; TP 20), $\mathrm{C}_{6} \mathrm{H}_{4} \mathrm{ClO}_{2}$ $\left(\mathrm{m} / \mathrm{z}\right.$ 142.9905; TP 21), $\mathrm{C}_{14} \mathrm{H}_{8} \mathrm{ClO}_{6}(\mathrm{~m} / \mathrm{z} 307.0015 ; \mathrm{TP} 22)$, $\mathrm{C}_{12} \mathrm{H}_{7} \mathrm{O}_{4}(\mathrm{~m} / \mathrm{z} 215.035 ; \mathrm{TP} 23), \mathrm{C}_{12} \mathrm{H}_{9} \mathrm{O}_{3}(\mathrm{~m} / \mathrm{z} 201.0557 ; \mathrm{TP}$ 25), $\mathrm{C}_{18} \mathrm{H}_{10} \mathrm{ClO}_{14}\left(\mathrm{~m} / z\right.$ 484.9765; TP 26), and $\mathrm{C}_{18} \mathrm{H}_{12} \mathrm{ClO}_{14}$ $(\mathrm{m} / \mathrm{z}$ 486.9921; TP 27). From these TPs, 25 are new proposed structures, while TP 6 and TP 21 have already been reported in previous studies. ${ }^{25,35}$

Most of the TPs were identified in both the photolysis and photocatalytic processes. The first four isomers of $\mathrm{C}_{18} \mathrm{H}_{9} \mathrm{C}_{12} \mathrm{O}_{5}$ (TPs 1-4) were identified in the photolysis process, while the five isomers (TPs 1-5) were found in the photocatalysis. TP $25\left(\mathrm{C}_{24} \mathrm{H}_{13} \mathrm{C}_{14} \mathrm{O}_{4}, m / z\right.$ 504.9573) was only present in the photolysis process. It was possible to elucidate the isomers because the compounds presented different chromatographic profiles with characteristic fragments.

The proposed TCS degradation steps (Figure 3) were based on the formation of a hydroxylated structure from TCS due to electrophilic attack of HO* or another ROS on dichlorobenzene or chlorophenol rings, or their hydroxylated derivatives, with dechlorination and hydrogen abstraction.

The identification of isomer forms (TPs 1-5, 8-9, 10-11, and 15-16) was in agreement with the results reported by Constantin et al. ${ }^{25}$ who identified intermediates present in different isomeric forms.

The $p$-dioxin derivatives, such as TPs 13 and 14, are well-known structures produced by abstraction of hydrogen from the phenolic moiety by $\mathrm{HO}^{-}$, with subsequent cyclization. ${ }^{36}$ Other structures generated from TCS included quinone and hydroquinone compounds (TPs 18, 20 , and 22); these types of structures were reported by Zhang and Huang. ${ }^{37}$ Coupling reactions may also occur during TCS oxidation when there is a large excess of phenol in the reaction mixture, generating structures such as TP 7 and TP 25. TPs such as 1-5, 8-9, 10-11, TP 7 and TP 25 can have hydroxylation substitutions at various positions (e.g., meta, para and ortho) with similar fragmentation patterns. For these TPs, the structural information from the LC-QTOF MS analysis (such as retention times and fragmentation patterns) is ill-suited for distinguish the structural position of hydroxylation. Thus, in Figure 3 the hydroxylation possibilities for these TPs are indicated in a general way.

The compound 4-chlorocatechol (TP 21) was reported by Constantin et al. ${ }^{25}$ to be formed during prolonged UV irradiation, followed by conversion to carboxylic acids. This TP was reported by Wu et al. ${ }^{35}$ to be a product of TCS treatment using zero-valent iron. For this reason, TP 21 increased over time during photolysis (Figure 4), while in the photocatalysis (Figure 5), it showed an increase followed by a slight decrease, possibly due to mineralization. ${ }^{38}$

The greatest amounts of the TPs were generated in the first $30 \mathrm{~min}$, after which, decreases were generally observed. In both processes, TP 6 was more resistant to oxidation, compared to the other TPs, as shown by the increase of its characteristic peak area in the first minutes of irradiation (Figures 4 and 5). Furthermore, it was degraded during a prolonged UV irradiation time (480 min), with decrease of the peak area towards the end of the irradiation period. TP 6 was also reported by Constantin et al. ${ }^{25}$ TPs 23 and 14 (photolysis) and TPs 15 and 22 (photocatalysis) showed persistence at the end of the assay period.

\section{Ecotoxicity assays}

Phytotoxicity assays with Lactuca sativa were used, because during the first days of seedling development there are numerous physiological processes. In these process, the presence of a toxic substance can interfere in germination and normal root development. ${ }^{12}$ On the other hand, acute toxicity in Daphnia magna can indicate toxic effects in aquatic ecosystems when treated effluents are discharged into surface water bodies. ${ }^{39}$

In the evaluation of phytotoxicity using $L$. sativa seeds, the root elongation values (see the SI section) were used to calculate the relative growth index (RGI). The results are provided in Table 3. The RGI values were divided into three categories, according to the observed effects: $(i)$ inhibition of root elongation $(0<\mathrm{RGI}<0.8)$, (ii) no significant effects $(0.8 \leq \mathrm{RGI} \leq 1.2)$, and (iii) stimulation of root elongation (RGI > 1.2). ${ }^{11}$ Acute toxicity towards Daphnia magna was expressed as toxic units (TU) (Table 3), after calculation of the $\mathrm{EC}_{50}$ values (Tables S4-S6, in the SI section).

It was observed that before the treatments, the TCS solution was toxic towards the two organisms tested. This was expected for D. magna, because the initial TCS concentration was well above its $\mathrm{EC}_{50}$ value 
(0.23-0.39 $\left.\mathrm{mg} \mathrm{L}^{-1}\right) .{ }^{3}$ For L. sativa, no $\mathrm{EC}_{50}$ data were found in the literature. However, studies evaluating the TCS effects, among other emerging contaminants, have shown phytotoxicity in several plants, at concentrations in the $\mathrm{mg} \mathrm{L}^{-1}$ range. ${ }^{40}$ In both the photolysis and photocatalysis processes, toxicity was observed after $10 \mathrm{~min}$ of reaction,

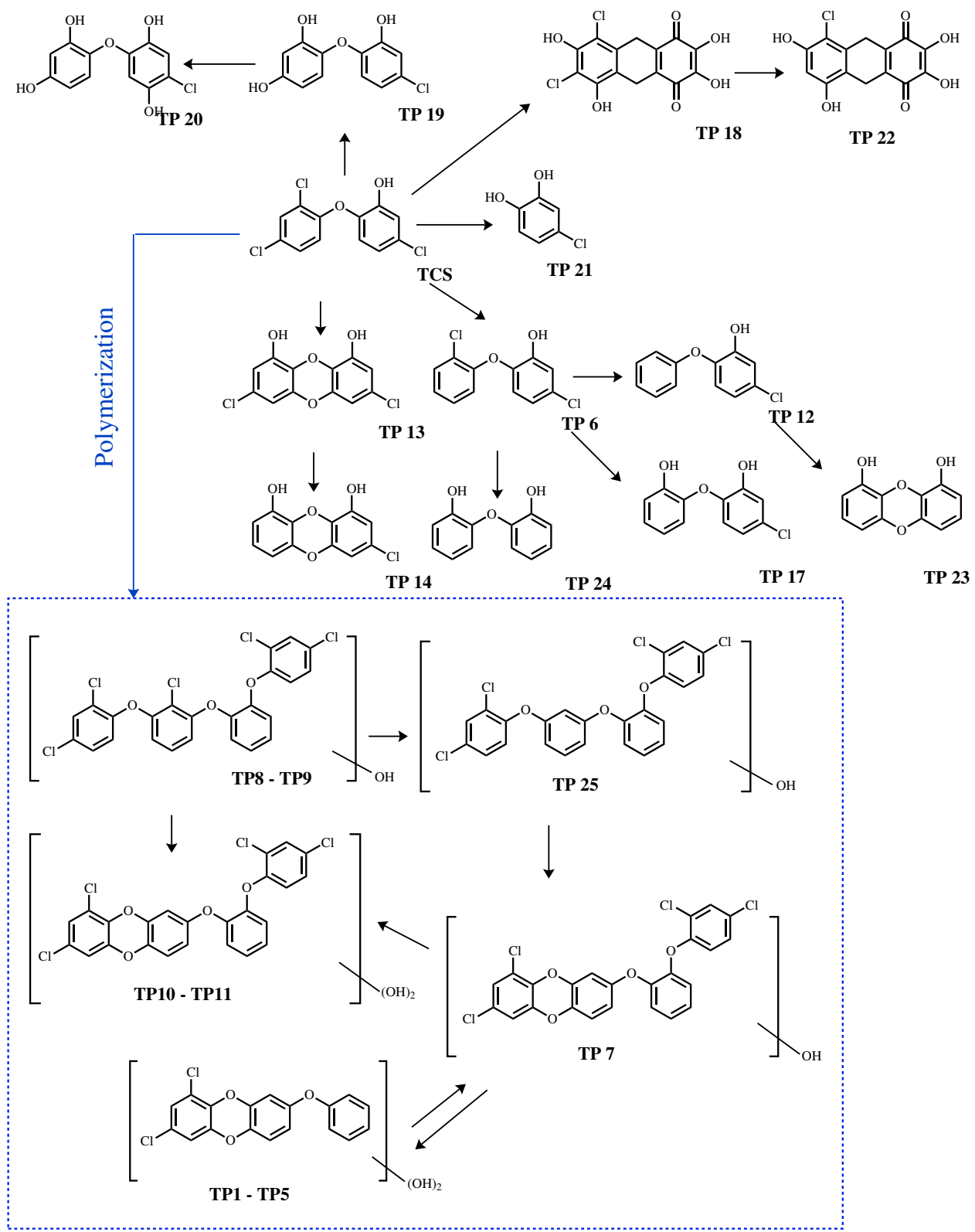

Figure 3. Proposed transformation products (TPs) tentatively identified for the degradation of triclosan using the $\mathrm{UV}^{\mathrm{TiO}} \mathrm{O}_{2}$ system.
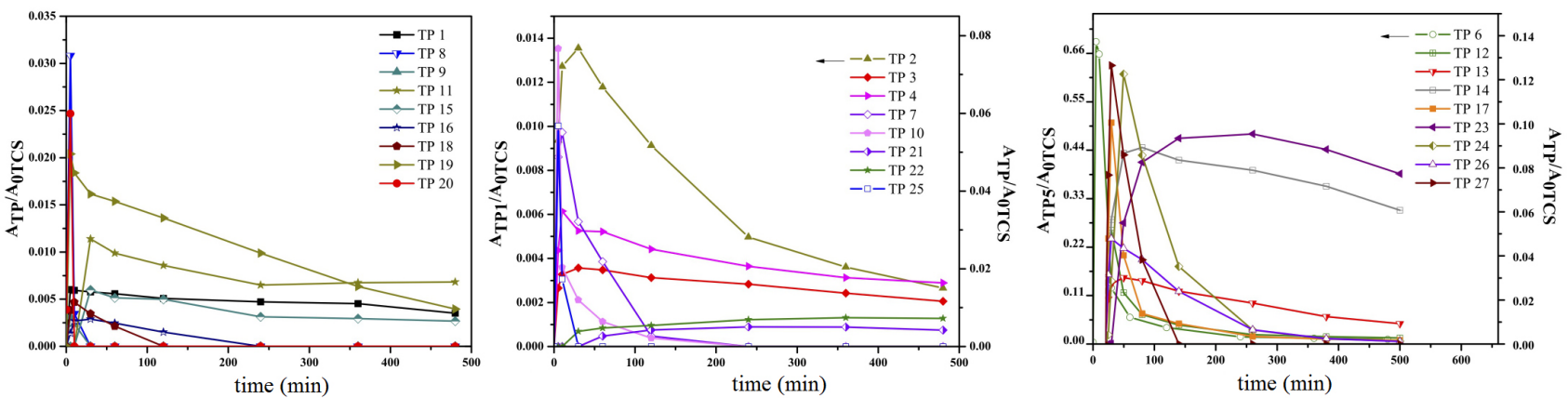

Figure 4. Profiles of transformation products (TPs) formed during photolysis. 

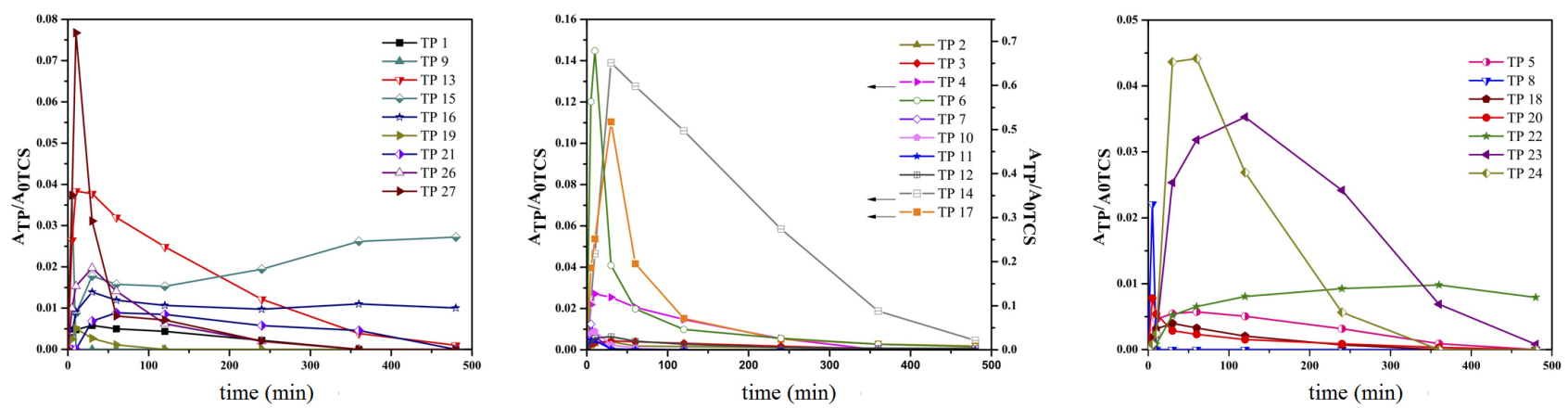

Figure 5. Profiles of transformation products (TPs) formed during photocatalysis.

although the effects were lower, compared to those observed initially, especially for D. magna. Before treatment, the TU value was 12.5 , while a decrease to around 2 was observed after $10 \mathrm{~min}$ of reaction, for both processes. This could be attributed to the decrease of the TCS concentration (Figure 2), with the appearance of TPs (Figures 4 and 5). Higher chromatographic peak areas were associated with the greater presence of a particular TP. At 5 and $10 \mathrm{~min}$ of treatment, the greatest peak area was shown by TP 5 , which is an isomer of $\mathrm{C}_{18} \mathrm{H}_{9} \mathrm{Cl}_{2} \mathrm{O}_{5}$, as mentioned above. After $120 \mathrm{~min}$, acute toxicity was only observed for the photolysis process. Despite the higher occurrence of TP 13 (a $p$-dioxin derivative) in both processes, the faster mineralization rate of the photocatalysis process could have contributed to the lower concentrations of the formed TPs. At $480 \mathrm{~min}$, the photocatalysis process only showed toxicity towards $L$. sativa, which could have been due to the presence of TP 14 (a p-dioxin derivative) and TP 21 (4-chlorocatechol) in this process. The toxicity could not be attributed to any single TP since each sample was a complex mixture of TCS and its TPs. However, some of the identified TPs have known toxicity, such as $p$-dioxins, ${ }^{41}$ quinones, and organochlorine compounds. ${ }^{42}$ After $16 \mathrm{~h}$, the toxicity was completely removed in both procedures. The observed results were probably associated with the higher absorption of the anionic form of TCS (phenolate).

\section{Conclusions}

Both photolysis and $\mathrm{UV} / \mathrm{TiO}_{2}$ photocatalysis were highly effective in degrading TCS. However, a significant difference between the two processes was observed for TCS mineralization, with photocatalysis being $50 \%$ more efficient than photolysis, at $180 \mathrm{~min}$ of reaction, confirming the importance of use of the catalyst. Twenty-seven TPs were identified, of which twenty-five were new proposed TPs with hydroxylated structures, whose formation involved dechlorination and hydrogen abstraction from TCS. Degradation routes were proposed for the TPs found.
Table 3. Phytotoxicity towards Lactuca sativa seeds and acute toxicity towards Daphnia magna, using triclosan solution $\left(10.0 \mathrm{mg} \mathrm{L}^{-1}\right)$ submitted to the photolysis and heterogeneous photocatalysis processes

\begin{tabular}{lcccccc}
\hline \multirow{2}{*}{ time / min } & \multicolumn{2}{c}{ Photolysis } & & \multicolumn{2}{c}{ Photocatalysis } \\
\cline { 2 - 3 } \cline { 5 - 6 } & L. sativa & D. magna $(\mathrm{TU})$ & & L. sativa & D. magna $(\mathrm{TU})$ \\
\hline 0 & $\mathrm{I}$ & 12.5 & & $\mathrm{I}$ & 12.5 \\
5 & $\mathrm{I}$ & 1.4 & & $\mathrm{I}$ & 0 \\
10 & NSE & 1.9 & & $\mathrm{I}$ & 2.1 \\
30 & NSE & 0 & & NSE & 0 \\
60 & NSE & 0 & & NSE & 0 \\
120 & $\mathrm{I}$ & 4.3 & & NSE & 0 \\
240 & NSE & 0 & & NSE & 0 \\
360 & NSE & 0 & & NSE & 0 \\
480 & NSE & 0 & & I & 0 \\
$16 \mathrm{~h}$ & NSE & 0 & & NSE & 0 \\
\hline
\end{tabular}

TU: toxic unit; I: root growth inhibition; NSE: no significant effect.

Similar compounds were formed in both processes, although the photocatalysis resulted in fewer compounds remaining in the solution. Ecotoxicity assessments showed that triclosan and some of the major TPs formed after photolysis and photocatalysis had harmful effects in Lactuca sativa and Daphnia magna. However, after $16 \mathrm{~h}$ of treatment, both procedures resulted in the complete removal of toxicity.

\section{Supplementary Information}

Supplementary data are available free of charge at http://jbcs.sbq.org.br as PDF file.

\section{Acknowledgments}

This work was supported by CNPq (grants 477962/2013-0 and 444110/2014-3) and was financed in part by Coordenação de Aperfeiçoamento de Pessoal de Nível Superior, Brasil (CAPES, Finance Code 001). The authors are grateful to CLABMU (Complex of Multiuser Laboratories of UEPG), the Federal University of Technology of Paraná, and the State University of Maringá for the analyses. 


\section{Author Contributions}

V.S. K. was responsible for investigation, methodology, data curation and writing original draft; E. C. L. for data curation and writing (review and editing); A. D. for data curation and software; M. F. G. for methodology; V. C. S. P. for methodology; A. M. F. for formal analysis and validation; C. S. for conceptualization and validation; E. S. C. for conceptualization and supervision; E. R. L. T. for conceptualization, funding acquisition and project administration.

\section{References}

1. Yueh, M.; Tukey, R. H.; Annu. Rev. Pharmocol. Toxicol. 2016, 56, 251.

2. Azarpira, H.; Sadani, M.; Abtahi, M.; Vaezi, N.; Rezaei, S.; J. Photochem. Photobiol., A 2019, 371, 423.

3. Orvos, R. D.; Versteeg, J. D.; Inauen, J.; Capdevielle, M.; Rothenstein, A.; Environ. Toxicol. Chem. 2002, 21, 1338.

4. Zhang, Q.; Li, C.; Li, T.; Chem. Eng. J. 2013, 217, 407.

5. Lumbaque, E. C.; Sirtori, C.; Vilar, V. J. P. ; Sci. Total Environ. 2020, 743, 140629.

6. Tiburtius, E. R. L.; Scheffer, E. W. O.; Rev. Virtual Quim. 2014, $6,1144$.

7. Qiao, X.; Zheng, X.; Xie, Q.; Yang, X.; Xiao, J.; Xue, W.; Chen, J.; J. Hazard. Mater. 2014, 275, 210.

8. Gomes Jr., O.; Silva, V. M.; Machado, A. E. H.; Sirtori, C.; Lemos, C. R.; Freitas, A. M.; Trovó, A. G.; J. Environ. Manage. 2018, 213, 20.

9. Sirtori, C.; Zapata, A.; Gernjak, W.; Malato, S.; Agüera, A.; Chemosphere 2012, 88, 627.

10. Statistica, version 7.0; Statsoft, USA, Tulsa, OK, 2007.

11. Young, B. J.; Riera, N. I.; Beily, M. E.; Bres, P. A.; Crespo, D. C.; Ronco, A. E.; Ecotoxicol. Environ. Saf. 2012, 76, 182.

12. Sobrero, M. C.; Ronco, A.; Ensayo de Toxicidad Aguda con Semillas de Lechuga Lactuca sativa L., vol. 3; Secretaria de Medio Ambiente y Recursos Naturales: México, 2004.

13. Garcia, J. C.; Simionato, J. I.; Almeida, V. C.; Palácio, S. M.; Rossi, F. L.; Schneider, M. V.; de Souza, N. E. ; J. Braz. Chem. Soc. 2009, 20, 1589.

14. BioEstat, versão 5.3; Instituto Mamirauá, Tefé, AM, Brazil, 2019.

15. ABNT NBR ISO/IEC 12713: Requisitos Gerais para Competência de Laboratórios de Ensaio e Calibração, ABNT: Rio de Janeiro, 2016.

16. Son, H. S.; Ko, G.; Zoh, K. D.; J. Hazard. Mater. 2009, 166, 954.

17. Abdel-Maksoud, Y. K.; Imam, E.; Ramadan, A. R.; Sol. Energy 2018, 170, 323.

18. Zúñiga-Benítez, H.; Peñuela, G. A.; Environ. Sci. Pollut. Res.
2017, 24, 6022.

19. Chemicalize: Instant Cheminformatics Solutions Software, available at http://www.chemaxon.com, accessed in April 2021.

20. Nosaka, Y.; Nosaka, A. Y.; Chem. Rev. 2017, 117, 11302.

21. Li, X.; Chen, C.; Zhao, J.; Langmuir 2001, 17, 4118.

22. Kitsiou, V.; Zachariadis, G. A.; Lambropoulou, D. A.; Tsiplakides, D.; Poulios, I.; J. Environ. Chem. Eng. 2018, 6, 2409.

23. Cao, H.; Lin, X.; Zhan, H.; Zhang, H.; Lin, J.; Chemosphere 2013, 90, 1514.

24. Jin, X.; Zhou, X.; Sun, P.; Lin, S.; Cao, W.; Li, Z.; Liu, W.; Chemosphere 2019, 237, 124433.

25. Constantin, L. A.; Nitoi, I.; Cristea, N. I.; Constantin, M. A.; J. Ind. Eng. Chem. 2018, 58, 155.

26. Zhang, Y. N.; Xie, Q.; Chen, J.; Li, Y.; Fu, Z.; J. Hazard. Mater. 2015, 300, 354.

27. Martínez-Zapata, M.; Aristizábal, C.; Peñuela, G.; J. Photochem. Photobiol., A 2013, 251, 41.

28. Iovino, P.; Chianese, S.; Prisciandaro, M.; Musmarra, D.; Chem. Eng. J. 2019, 377, 121045.

29. Kumar, K. V.; Porkodi, K.; Rocha, F.; Catal. Commun. 2008, 9,82 .

30. El-Bindary, A. A.; El-Marsafy, S. M.; El-Maddah, A. A.; J. Mol. Struct. 2019, 1191, 76

31. Gar Alalm, M.; Tawfik, A.; Ookawara, S.; J. Environ. Chem. Eng. 2016, 4, 1929.

32. Antonopoulou, M.; Konstantinou, I.; Appl. Catal., A 2016, 515, 136.

33. Chan, K. H.; Chu, W.; Chemosphere 2003, 51, 305.

34. Marson, E. O.; Paniagua, C. E. S.; Costa-Serge, N. M.; Sousa, R. M. F.; Silva, G. D.; Becker, R. W.; Sirtori, C.; Starling, M. C. V. M.; Carvalho, S. R.; Trovó, A. G.; Environ. Sci. Pollut. Res. 2020, DOI: 10.1007/s11356-020-09756-3.

35. Wu, Y.; Lin, L.; Suanon, F.; Hu, A.; Sun, Y. N.; Yu, Z. M.; Yu, C. P.; Sun, Q.; Chem. Eng. J. 2018, 346, 24.

36. Vega, L. P.; Soltan, J.; Peñuela, G. A.; Environ. Sci. Pollut. Res. 2019, 26, 4450.

37. Zhang, H.; Huang, C.-H.; Environ. Sci. Technol. 2003, 37, 2421.

38. Yang, B.; Ying, G.-G.; Zhao, J.-L.; Zhang, L.-J.; Fang, Y.-X.; Nghiem, L. D.; J. Hazard. Mater. 2011, 186, 227.

39. Rizzo, L.; Water Res. 2011, 45, 4311.

40. Bartrons, M.; Peñuelas, J.; Trends Plant Sci. 2017, 22, 194.

41. Beyer, J.; Petersen, K.; Song, Y.; Ruus, A.; Grung, M.; Bakke, T.; Tollefsen, K. E.; Mar. Environ. Res. 2014, 96, 81.

42. Bedoux, G.; Roig, B.; Thomas, O.; Dupont, V.; Le Bot, B.; Environ. Sci. Pollut. Res. 2012, 19, 1044.

Submitted: February 17, 2021

Published online: April 14, 2021 